\title{
BEHAVIOR OF PRECAST PRESTRESSED HOLLOW CORE SLABS WITH OPENINGS: EXPERIMENTAL STUDY
}

\author{
A. F. EL-khouly, N. N. Meleka, M. A. Tayel, and K. M. Heiza. \\ Department of Civil Engineering, Faculty of Engineering \\ Menoufia University, Egypt
}

\begin{abstract}
A hollow core slab is a precast prestressed concrete member with longitudinal hollow cores that reduce its self-weight. This paper presents the effects of openings on flexural and shear behavior of precast prestressed hollow core slabs. Three full-scale hollow core slabs of dimensions 4100x1200x160 mm were tested. One slab without opening is considered as a control specimen. The second slab with a central opening with dimensions $250 \times 250 \mathrm{~mm}$ at mid of span was tested to investigate the effect of this opening on the flexure capacity. The third slab has an opening at mid of one-third of span was tested to investigate the effect of the opening on shear capacity of hollow core slab. All specimens were tested under four loading points until failure. Test results showed that the opening at mid-span decreases the flexure capacity of the slab. The failure load of the slab in this case is decreased by about $11.40 \%$. The failure modes of the hollow core slab with a central opening as well as the control slab were ductile. The presence of the opening at maximum shear affect the slab behavior badly. It caused a sudden failure. The reduction of the failure load was about $21 \%$.

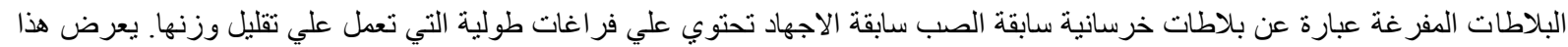

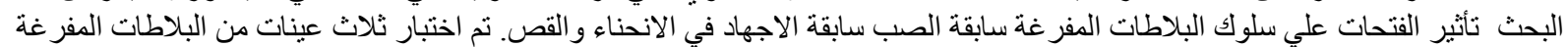

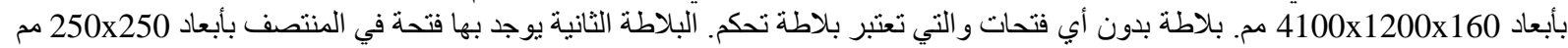

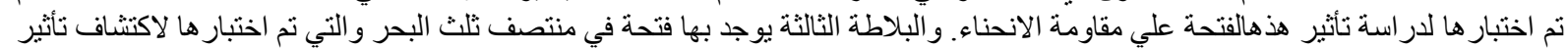

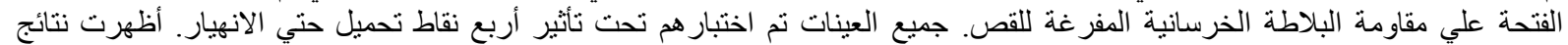

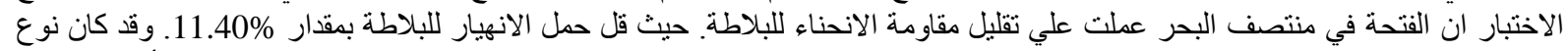

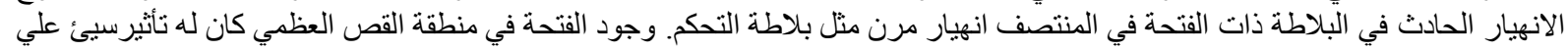
البلاطة حيث سبب انهيار مفاجئ في العينة. نسبة الانخفاض الحادث فئه في حمل الانهيار كان
\end{abstract}

\section{INTRODUCTION}

Precast prestressed concrete Hollow-Core (HC) slabs have been used in many civil engineering structures including residential and commercial buildings, parking structures, and short span bridges [1]. A HC slab consists of 40-50\% voids running along the length of slab to reduce its self-weight and thereby leading to economy in construction. HC slabs have an important market presence in many countries. Prestressed reinforcement improves the serviceability performance of $\mathrm{HC}$ slabs compared to plain slabs (those without voids), increasing the cracking moment as well as the load-bearing capacity. Span lengths of up to $16 \mathrm{~m}$ and high load levels can be achieved with HC slab floor systems [2, 3].

$\mathrm{HC}$ slabs have been made for several years. In the early years of their appearance in the industry HC slabs were made by many different systems. Some were produced in fixed forms and some in movable forms. The variations were mostly in the coring system. Nowadays, the large-scale expansion of the construction industry created the need for more efficient and economical ways to produce HC slabs. The technology which is now used is producing by extruding technology in large longitudinal forms .
When the concrete is sufficiently hardened, the panels and strands are cut to the appropriate length which may vary to whatever dimension the customer requirements. This process excludes the use of any shear reinforcement and the strands are anchored only by bond [4, 5].

It is very common to have openings in slabs and wall panels for accommodating different building services. Openings which require removal of small areas of concrete and without cutting any prestressing strands are typically termed as non-structural openings. They would not cause any adverse effect on the strength and behavior of slabs. Large openings (structural openings) which require cutting of strands will cause disturbance in the load distribution and makes the slabs as a weak link in the whole structure. In general, openings are usually taken in consideration during the design procedure. However, in some situations openings are provided after construction in locations where necessary design precautions were not taken $[6$, 7].

The objective of this paper is to investigate the effect of opening-which is not taken in consideration in the design of $\mathrm{HC}$ slabs. 


\section{EXPERIMENTAL PROGRAM}

\subsection{Test specimens}

Full-scale load test was conducted on three precast prestressed hollow-core slabs obtained from a local precast manufacturer (Modern Concrete for Precast and Prestressed Members). All specimens have a length of 4,100 mm, a depth of $160 \mathrm{~mm}$ and a width of 1,200 $\mathrm{mm}$. The first experimental specimen without any openings PPHCS1 is considered as control specimen, the second specimen, PPHCS2 has an opening $250 \times 250 \mathrm{~mm}$ at mid-span. The third specimen, PPHCS3 has an opening 250x250 mm at mid of one-third of the span. Each slab has nine longitudinal prestressed strands at the bottom of the slab (one strands per web)

with a diameter of $9.3 \mathrm{~mm}$. In the second specimen, to make the opening one strand (the mid strand) had to be cut. The cross section of the control specimen is shown in Fig. 1 and openings locations for other specimens are shown in Fig. 2.

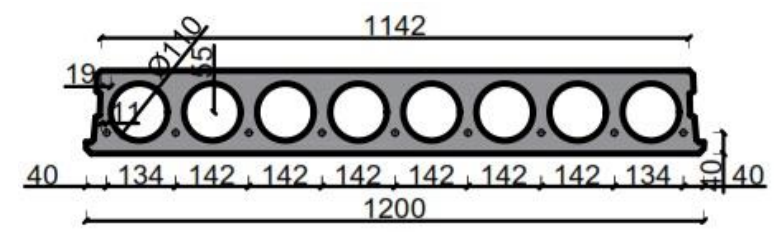

Fig. 1: Geometry of Precast Prestressed HC control slab

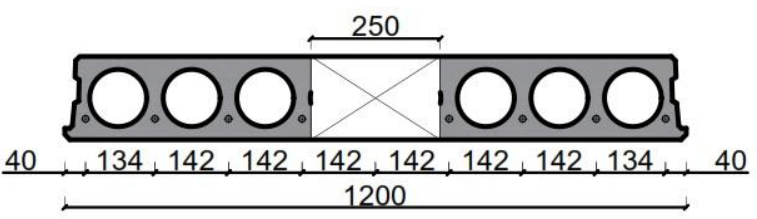

(a): Section A-A

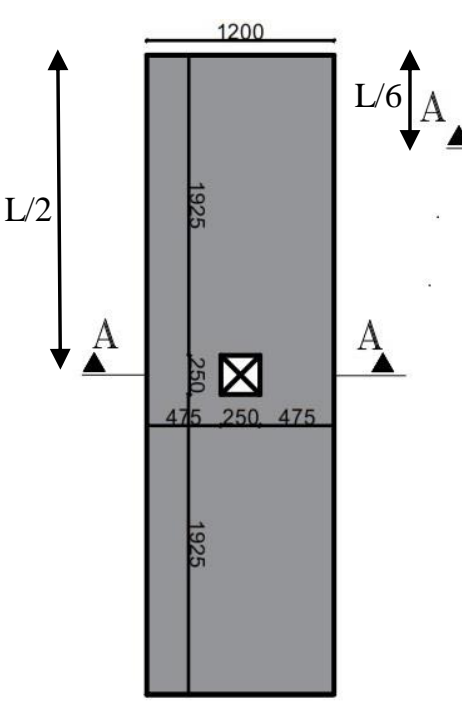

(b): Flexure opening

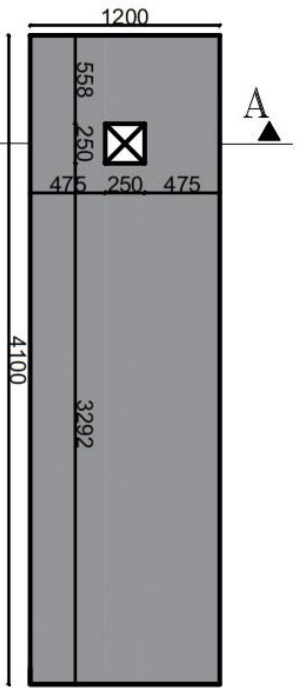

(c): Shear opening
Fig. 2: Openings locations for PPHCS2 and PPHCS3

\subsection{MATERIAL PROPERTIES}

\subsubsection{Concrete}

All the prestressed precast $\mathrm{HC}$ slabs were manufactured in the precast factory. The average 28day cube compressive strength of these slabs was 50 $\mathrm{MPa}$. The unit weight of concrete used was 2,400 $\mathrm{kg} / \mathrm{m}^{3}$.

\subsubsection{Prestressing strands}

Uncoated bright steel 7-wire P.C. strand $(9.3 \mathrm{~mm}$ nominal diameter) low- relaxation strands were used. Coupon tests were conducted and the average ultimate tensile strength and modulus of elasticity was found to be 1,860 MPa and $200 \mathrm{GPa}$; respectively.

\subsection{Test setup}

The specimens were tested under four point bending as illustrated in Fig.3. They were simply supported on the short edges. A $500 \mathrm{kN}$ hydraulic jack was used to apply the load which was transferred to the slab using a rigid longitudinal spreader beam. Two transverse I beams were used for applying uniformly distributed line loads along the width of slabs. The bottom simple supports were achieved using two I beams. The support and loading I beams were sufficiently stiffened to avoid any local buckling failure. The load was applied gradually for all the specimens tested in this study with constant value (5 $\mathrm{kN}$ per increment). Loading was paused intermittently to observe the failure progression, marking of cracks and get the dial gauge readings. The instrumentation of the specimens is shown in Fig.4.

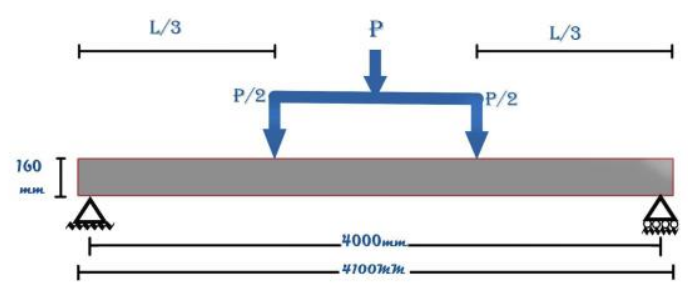

Fig. 3: Schematics of experimental setup

\subsubsection{Measuring Devices}

Five dial gauges were installed to measure the deflections at different points of the tested slab. One dial gauge was placed at mid-span, two dial gauges were placed under line loads, and last two dial gauges were placed at mid of one-third of span to measure deflection. The testing equipment and the test setup are shown in Fig.4. 


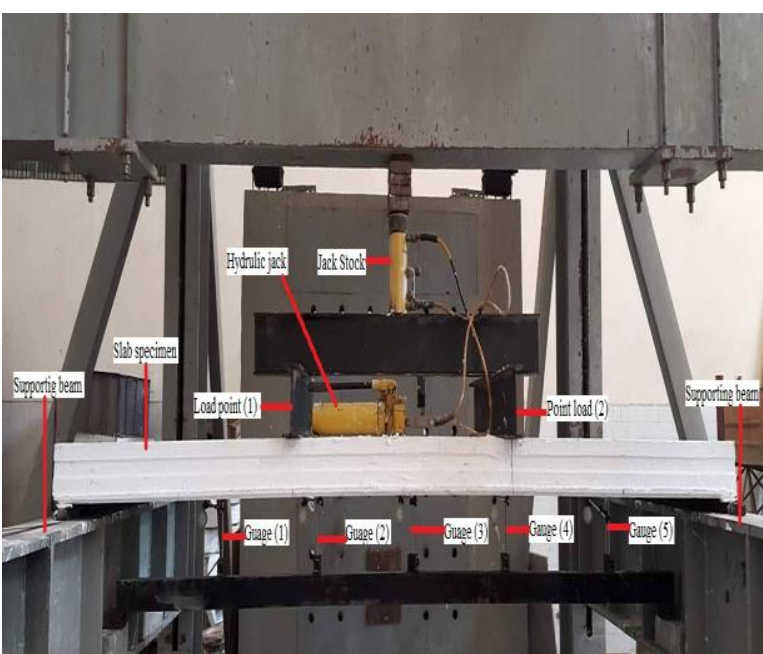

Fig. 4: Test setup and instrumentation

\section{RESULTS AND DISCUSSION}

\subsection{Load deflection behavior}

Load deflection curves of PPHCS1 and PPHCS2 at mid of span and under line load are presented in Fig. 5 and Fig. 6; respectively. The load deflection curve for control slab (PPHCS1) shows a typical underreinforced behavior for bending stresses. The slab was cracked in flexure at the bottom fiber after the tensile strength of concrete had reached. Cracking was reflected through a change in slope of the loaddisplacement curve. With further increase in the applied load, strands started resisting the load until their yielding. Soon after the yielding of the strands, load displacement curve flattened and no further increase in load resistance was observed. For second series (PPHCS2) load deflection curve shows same behavior of control slab but with decrease in the stiffness and capacity of the slab which is affected by the opening.

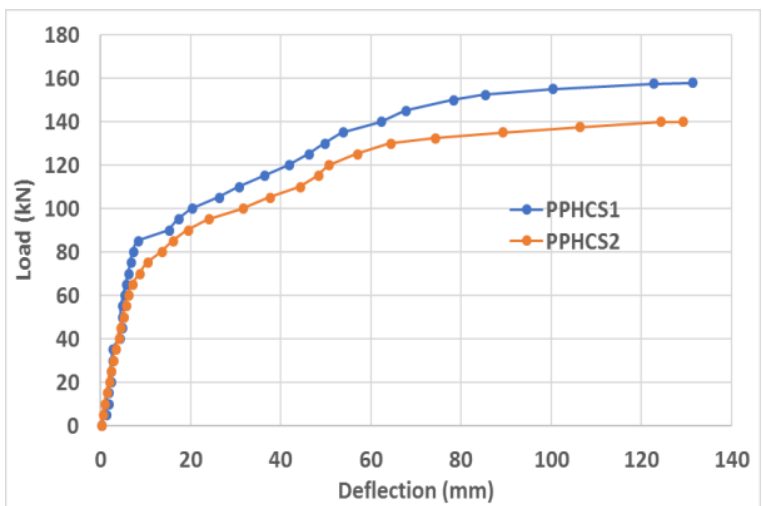

Fig. 5: Load-Deflection curve at mid-span for PPHCS1 and PPHCS2

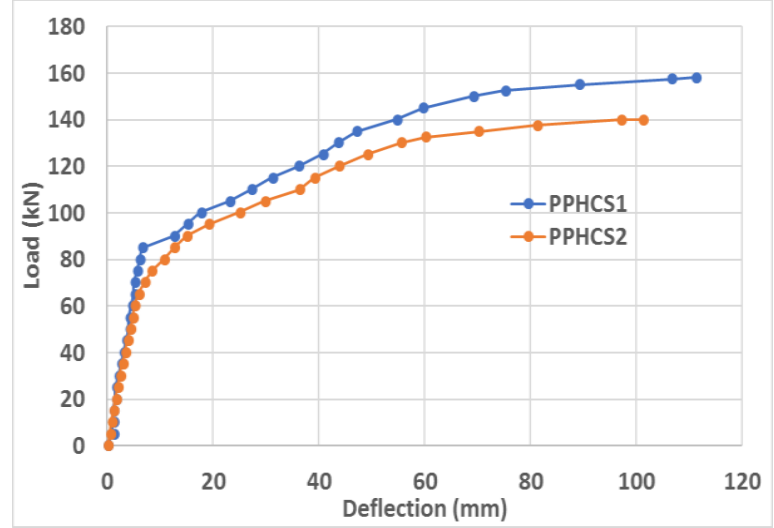

Fig. 6: Load-Deflection curve under the line load for PPHCS1 and PPHCS2

The load deflection curves of PPHCS1 and PPHCS3 at mid of span and under line load are shown in Fig.7 and Fig. 8; respectively.

For PPHCS3, during the first elastic range the specimen showed a very similar behavior as that of the PPHCS1. PPHCS3 specimen was still capable to resist load beyond the elastic range. Suddenly, the PPHCS3 specimen failed at an ultimate load of 125 $\mathrm{kN}$.

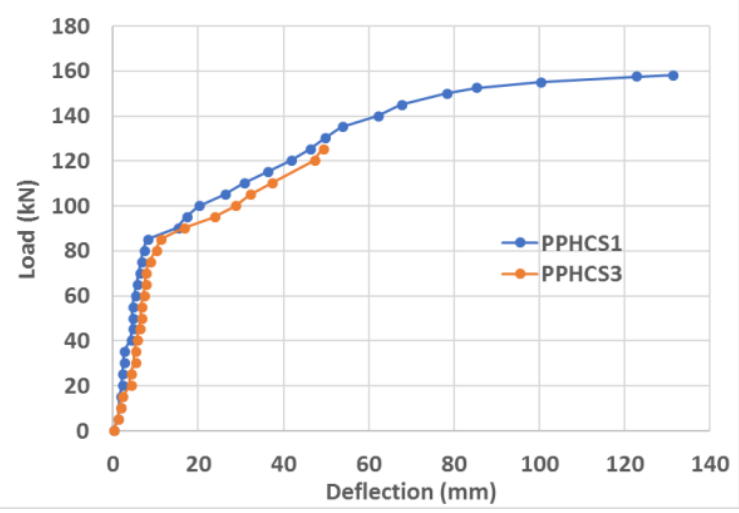

Fig. 7: Load-Deflection curve at mid-span for PPHCS1 and PPHCS3

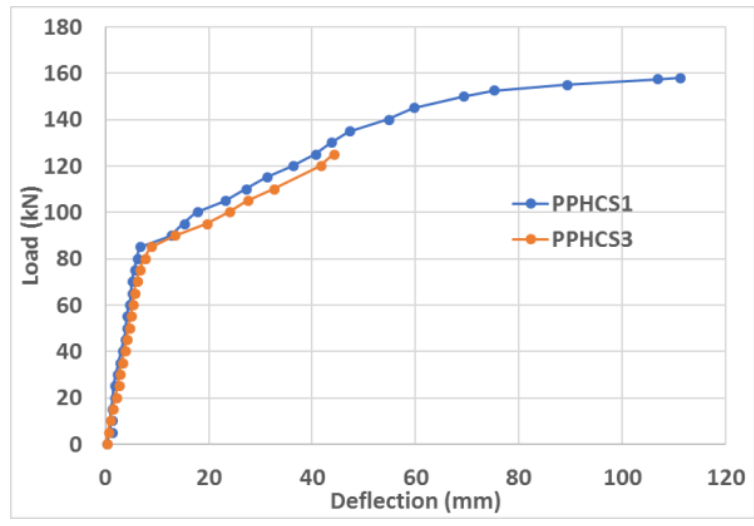

Fig. 8: Load-Deflection curve under the line load for PPHCS1 and PPHCS3 


\subsection{Cracking and failure mode}

First flexural crack in the control slab was observed at the tension region in the constant moment zone. Fig (9) shows that the first cracking loads were $85 \mathrm{kN}$ and $65 \mathrm{kN}$ for PPHCS1 and PPHCS2; respectively. More distributed cracks formed with further increase in loads along the length of specimen as shown in Figs 10,11 and 12 . Significant displacement ductility was observed at the failure indicating an under reinforced failure mode. Also, the failure loads were $158 \mathrm{kN}$ for PPHCS1 and $140 \mathrm{kN}$ for PPHCS2 specimens.

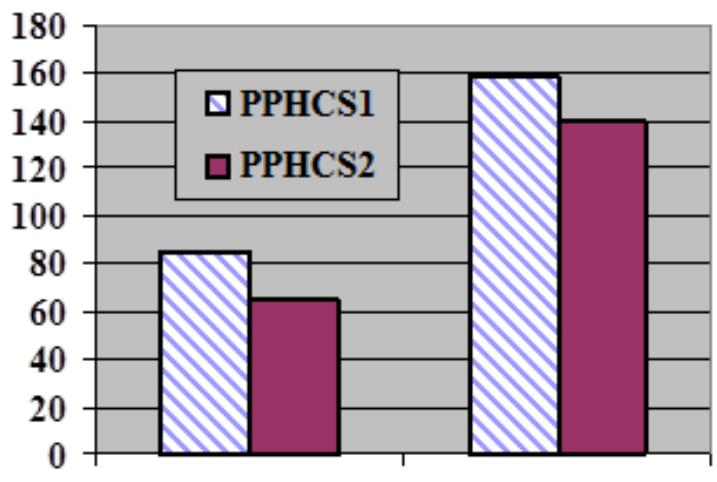

First cracking load Failure load (kN) $(\mathrm{kN})$

Fig. 9: Test results of PPHCS1 and PPHCS2 slabs

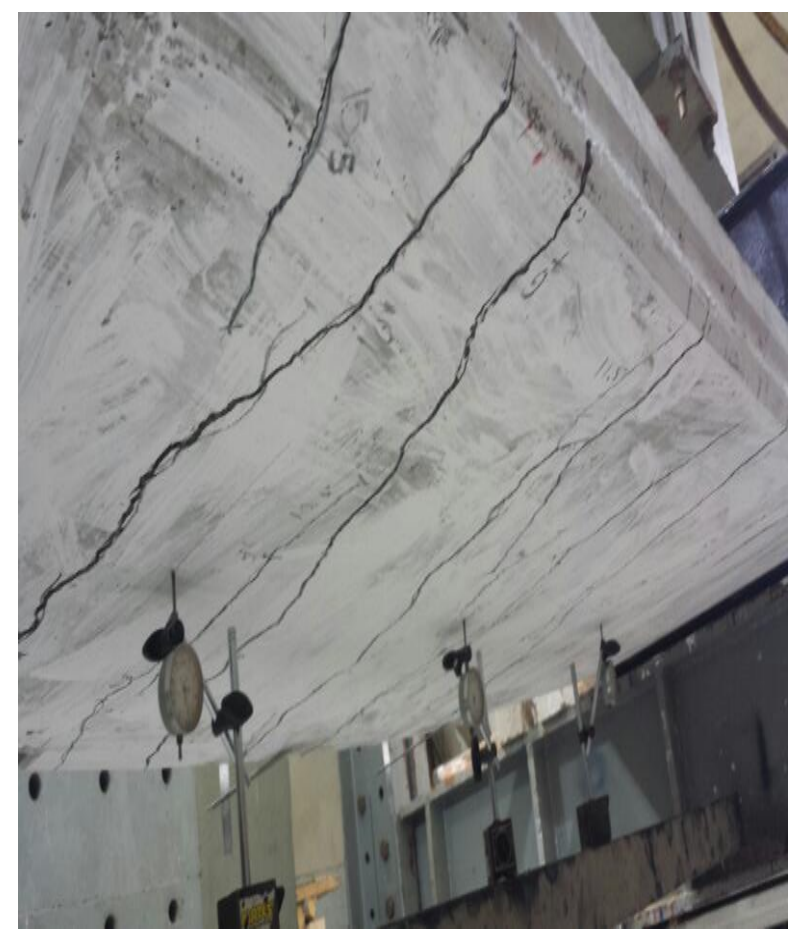

Fig. 10: Cracks pattern for PPHCS1 at failure

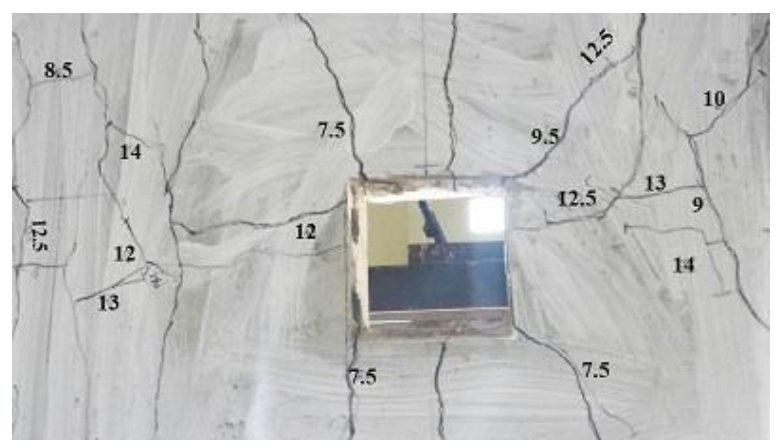

Fig. 11: Cracks pattern for PPHCS2 at failure

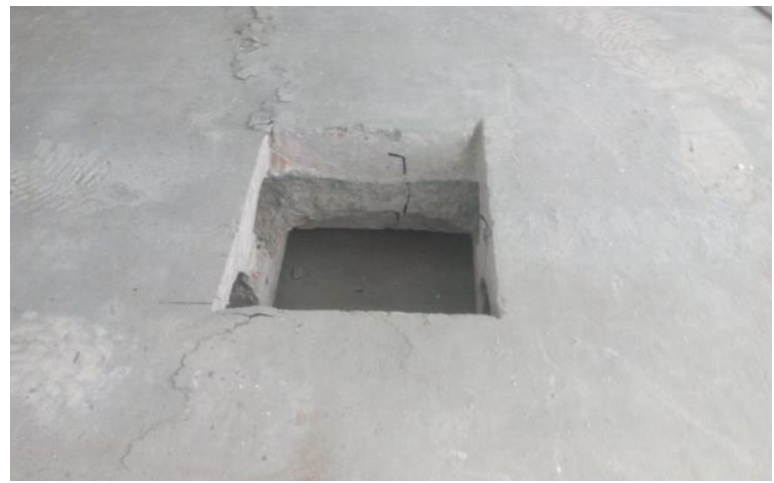

Fig. 12: Cracks pattern at top surface for PPHCS2

For PPHCS3, first flexural crack in the specimen was observed at the tension region in the constant moment zone. The first cracking load was $80 \mathrm{kN}$. Suddenly, specimen PPHCS3 failed at an ultimate load of 125 $\mathrm{kN}$. The failure mode is shown in Figs 13. The comparison of first cracking load and failure load between PPHCS1 and PPHCS3 is shown in Fig. 14.

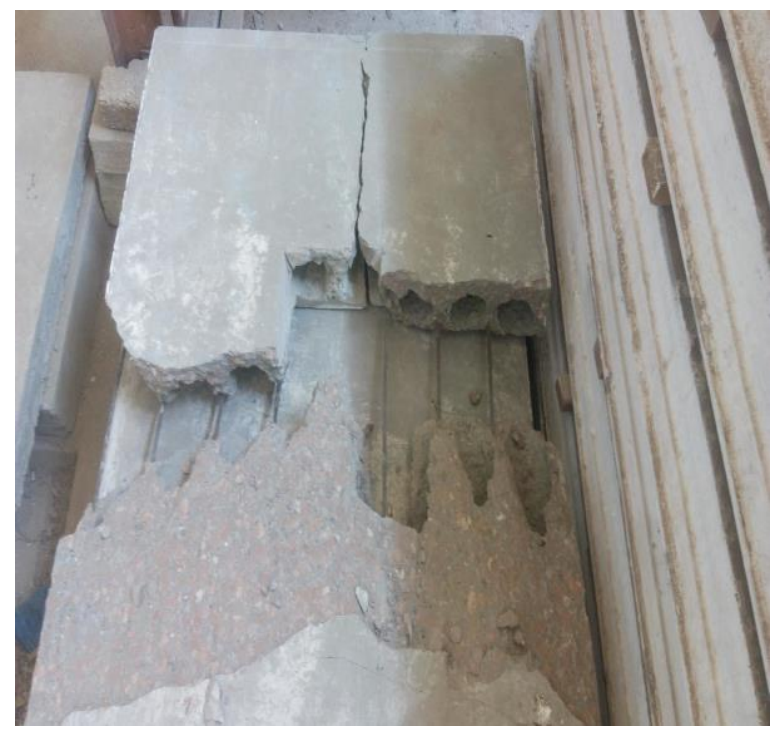

Fig. 13: Failure and Cracks pattern for PPHCS3 


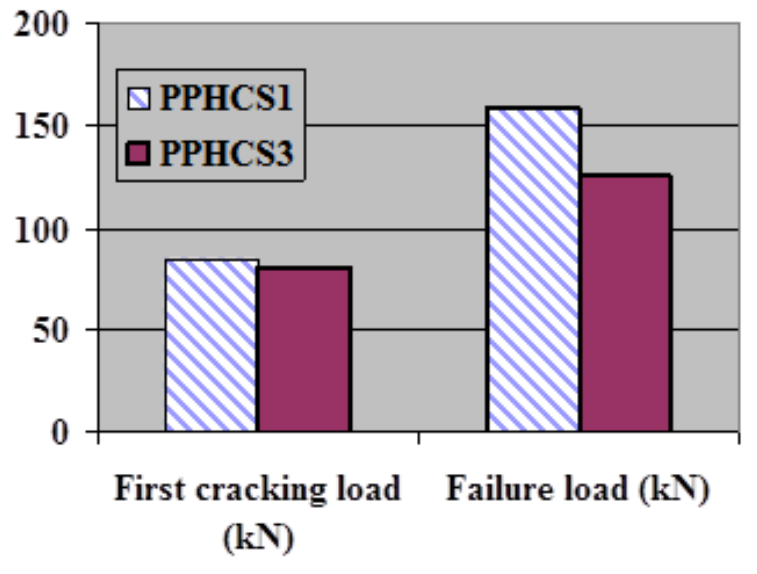

Fig. 14: Test results of PPHCS1 and PPHCS3 slabs

\section{Conclusions}

Full scale tests were carried out on flexural and shear behavior of prestressed precast hollow core slabs, PPHCS to investigate the behavior and capacity of slabs with and without opening at mid-span and mid of one-third of specimen. The following conclusions can be drawn as follows:

1. Making an opening at mid of span reduced the stiffness and decreased the flexure capacity of the slab. The first cracking load was decreased by about $23.50 \%$, and the failure load was decreased by $11.40 \%$ with respect to control slab results.

2. The opening at mid span did not affect the failure mode as it remained ductile as control slab specimen.

3. For the opening at mid of one third of span (at max shear), as there is no steel to resist the shear (only concrete) the opening had a very severe effect on slab at this zone as the specimen failed suddenly. The first cracking load and failure load was decreased by about $6 \%$ and $21 \%$; respectively with respect to control slab.

\section{References}

[1] S. I. HARUNA. (2014), "Flexural Behavior of Precast Prestressed Concrete Hollow Core Slabs with Cast-In-Place Concrete Topping," ATILIM UNIVERSITY.

[2] Sgambi L., Gkoumas K. and Bontempi F. (2014), "Genetic Algorithm Optimization of Precast Hollow Core Slabs", Computer and Concrete, 13(3):389 - 409.

[3] Pisanty A. and Regan P.E. (1991), "Direct Assessment of the Tensile Strength of the Web in Prestressed Precast Hollow-Core Slabs", Materials and Structures, 24(6): 451 - 455.

[4] Pisanty A., (1992), "The Shear Strength of Extruded Hollow-Core Slabs", Materials and Structures, 25(4): 224 - 230.

[5] Belleri A., Brunesi E., Nascimbene R., Pagani M, and Riva P., (2014), "Seismic Performance of Precast Industrial Facilities Following Major Earthquakes in the Italian Territory", Journal of Performance Constructed Facilities, ASCE.http://dx.doi.org/10.1061/(ASCE)CF.19435509.0000617.

[6] P. S. K. Sarma and S. S. Prakash. (2015), "Performance of Prestressed Hollow-Core Slabs with and without Cutouts," pp. 443 - 447.

[7] S. Kumar, S. Pachalla, and S. S. Prakash (2017), "Load Resistance and Failure Modes of GFRP Composite Strengthened Hollow Core Slabs with Openings," Mater. Struct., pp. 1-14 